\title{
Potential preventive role of Iranian Achillea wilhelmsii C. Koch essential oils in acetaminophen-induced hepatotoxicity
}

\author{
Abolfazl Dadkhah ${ }^{1 *}$, Faezeh Fatemi ${ }^{2}$, Shima Ababzadeh ${ }^{3}$, Kambiz Roshanaei ${ }^{4}$, Mahdi Alipour ${ }^{4}$ \\ and Bahareh Sadegh Tabrizi ${ }^{5}$
}

\begin{abstract}
Background: The essential oil of Achillea wilhelmsii C. Koch (100 \& 200 mg/kg b.w, i.p) was evaluated against acetaminophen induced hepatic injuries in rats. For this purpose, the activities of cytochrome P450 (CYP450), glutathione s-transferase (GST) and markers of liver injuries (ALT, AST, ALP) together with level of GSH measured analytically in time intervals $(2,4,8,16 \& 24 \mathrm{~h})$ after treatments confirmed by histophatological consideration in rat livers.

Results: Administration of acetaminophen (500 mg/kg bw, i.p) significantly increased the activity of CYP450 concomitant with increasing the release of ALT and AST. Whereas, GSH level and GST activity were decreased significantly after acetaminophen treatment. Treatment of rats with Achillea wilhelmsii essential oils significantly modulate these parameters to normal values. Also, histophatological analysis of liver biopsies was consistent with the biochemical findings.
\end{abstract}

Conclusion: The data led us to conclude the curative potential of Achillea wilhelmsii essential oils against APAP induced hepatic injuries.

Keywords: Achillea wilhelmsii C. Koch essential oils; Metabolizing enzymes; Acetaminophen; Rat; Liver

\section{Background}

Acetaminophen $\left(\mathrm{APAP}^{\mathrm{a}}\right)$ is a pain reliever and a fever reducer used extensively to treat many conditions such as headache, muscle aches, arthritis, backache, toothaches, colds, and fevers (Boyer and Rouff 1971; Vermeulen et al. 1992). The main problem with this medication is misuse through intentional or unintentional ingestion of supratherapeutic dosages, which usually lead to hepatic necrosis (Bond et al. 2003).

Acetaminophen is primarily metabolized into sulfate and glucuronide metabolites. A minor pathway through CYP450 had been also reported to yield a highly reactive metabolite, N-acetyl-p-benzoquinonimine (NAPQI). This metabolite is generally stabilized through conjugation with glutathione by glutathione s-transferase (GST)

\footnotetext{
*Correspondence: Dadkhah_bio@yahoo.com

'Department of Medicine, Faculty of Medicine, Qom Branch, Islamic Azad University, Qom, Iran

Full list of author information is available at the end of the article
}

(Henderson et al. 2000) and eliminated via the kidney. Following overdose, and possibly also in extensive and ultrarapid metabolizers, this detoxification pathway becomes saturated, and, as a consequence, NAPQI accumulates (Dong et al. 2000; Hendrickson and Kenneth 2006; Borne 1995). Too much acetaminophen can overwhelm the way the liver normally functions leading to organ failure (Khashab et al. 2007; Hawkins et al. 2007; Larson et al. 2005). Our recent studies together with others indicated that reactive oxygen and nitrogen intermediates, produced by hepatic paranchymal and non-paranchymal cells are believed to be important factors contributing to APAP-induced injury (Dadkhah et al. 2006, 2007; Michael et al. 1999; Laskin et al. 1995; Sener et al. 2003). There is increasing interest in the antioxidants of natural origin because they could suppress the oxidative damage of a tissue by stimulating the natural defence system. Consequently, (c) 2014 Dadkhah et al.; licensee Springer. This is an Open Access article distributed under the terms of the Creative Commons Attribution License (http://creativecommons.org/licenses/by/4.0), which permits unrestricted use, distribution, and reproduction in any medium, provided the original work is properly credited. 
application of natural antioxidants without any side effects for modulation of liver oxidative damages can not be ruled out.

Achillea wilhelmsii C. Koch (Asteraceae) wildly grows in different parts of Iran used in traditional medicine for gastrointestinal disorders such as antispasmotic, choleretic, antiulcer, antibacterial and hepatoprotective, antioxidant, anti-inflammatory, anti-allergic, antihypertensive and antihyperlipidemic properties (Nemeth and Bernath 2008; Candan et al. 2003; Yaeesh et al. 2006; Asgary et al. 2000; Fathi et al. 2011; Goldberg et al. 1969; Benedek et al. 2006; Cavalcanti et al. 2006).
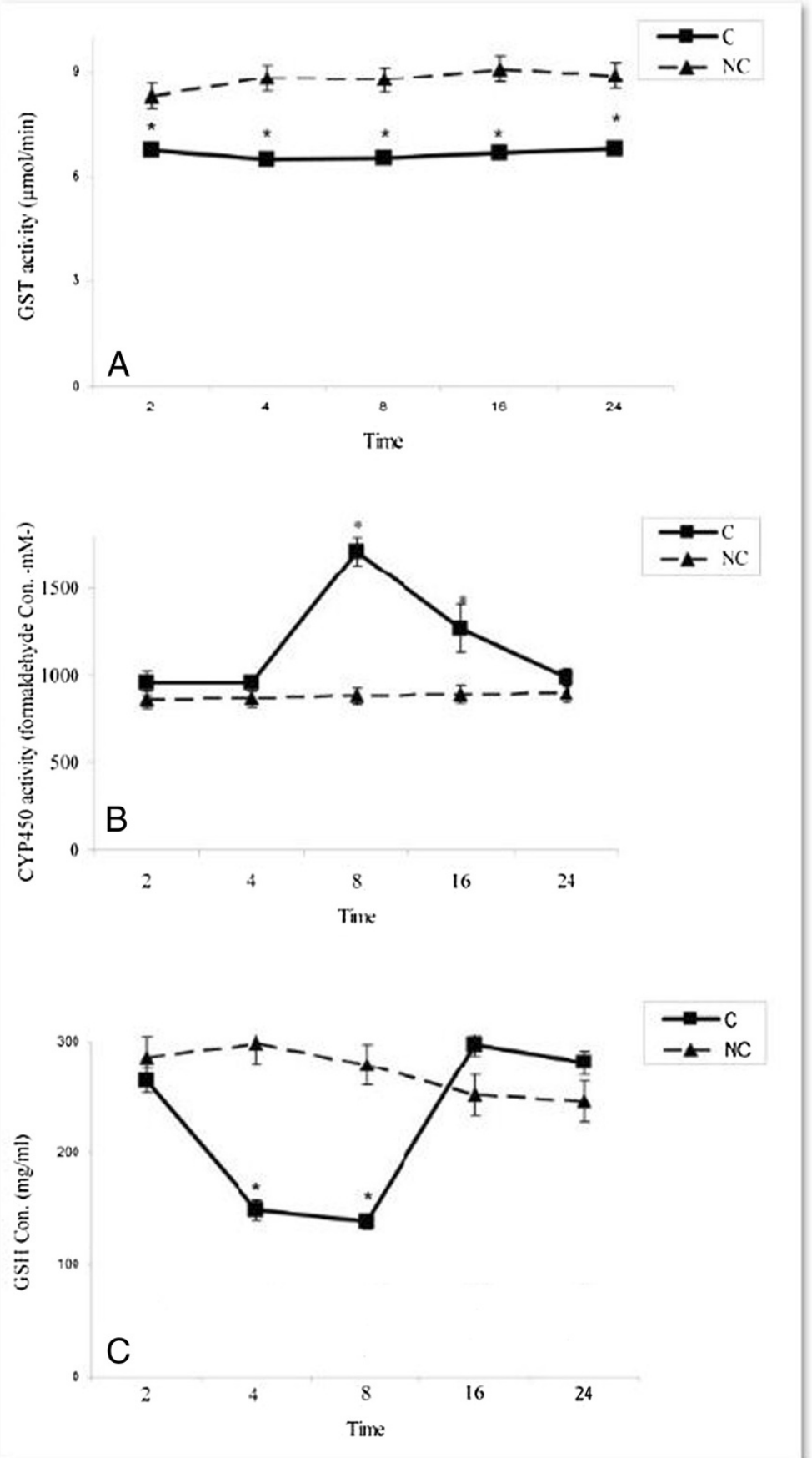

Figure 1 Time-course changes in xenobiotic metabolizing enzyme activities and GSH level in rats treated with APAP in compare to negative controls. A) GST activities B) CYP450 activities C) GSH levels. In negative control group (NC), the APAP vehicle i.e. $400 \mu$ l DMSO was only injected. In control group (C), the acetaminophen (500 mg/kg bw) dissolved in 400 ul DMSO was i.p injected. Data are mean \pm S.E.M. of five samples obtained from five animals in each group. $\left(^{*}\right)$ denote significantly different from the respective negative control group $(P<0.05)$. 
Our recent study indicated the in vitro antioxidant activity of Achillea wilhelmsii essential oils with the $\mathrm{p}-$ cymene' terpinolene and $\alpha$-thujene as the major compounds (Roshanaei et al. 2012). Continuing this, this research for the first time, pointed out to the effects of Achillea wilhelmsii crude extract oils on amending the acetaminophen metabolism aiming the drug toxicity reduction. For this purpose, the most important xenobiotic metabolizing enzymes such as cytochrome P450 (CYP450) and glutathione s-transferase (GST) activities and the level of glutathione (GSH) together with the activities of liver injury markers (Alanine transaminase (ALT), Aspartate transaminase (AST) and Alkaline phosphatase (ALP)) were measured experimentally. Additionally, the histophatological assessment was also accomplished to validate the findings.

\section{Methods}

\section{Plant preparation}

Fresh Achillea wilhelmsii C. Koch grown in Iran was collected from Qazvin province. The plant was authenticated by an expert botanist, Prof. Mozaffarian V. Oil extraction was carried out using a Clevenger-type apparatus following component identification by GC/MS analysis. Then, the radical scavenging activity of the oils was measured through radical-scavenging and antioxidant activities (DPPH and B-Carotene-linoleic acid assays) of the oils (Roshanaei et al. 2012).

\section{Animal treatments}

Male Wistar rats were used throughout this study. Animals were obtained from Pasteur Institute of Iran and maintained in our animal house facilities. Adult animals



Figure 2 Effect of $A$. wilhelmsii essential oils on GST activities after APAP administration. (A) $4 \mathrm{~h}$ after APAP administration (B) $8 \mathrm{~h}$ after APAP administration. In negative control group (NC), the APAP vehicle i.e. $400 \mu \mathrm{l}$ DMSO was only injected. In control group (C), the acetaminophen (500 mg/kg bw) dissolved in $400 \mu$ DMSO was i.p injected. In treatment groups (A100 and A200), the essential oils prepared from the plants at two different doses i.e. 100 and $200 \mathrm{mg} / \mathrm{kg}$ b.w were diluted in $400 \mu \mathrm{l}$ DMSO and injected i.p immediately after acetaminophen administration. In positive control group (BHT), the BHT (10 mg/kg b.w) dissolved in $400 \mu$ l DMSO was injected i.p immediately after acetaminophen administration. Data are mean \pm S.E.M. of five samples obtained from five animals in each group. $\left(^{*}\right)$ denote significantly different from the respective negative control group $(P<0.05)$. $\left.{ }^{* *}\right)$ denote significantly different from the respective control group $(P<0.05)$. 
were $3-4$ months of age, weighing $180 \pm 20 \mathrm{~g}$. They were maintained on a commercial pellet food and tap water ad libitum. Animal studies were approved by the Medical Ethics Committee of Tarbiat Modares University. This Ethics Committee was based on the World Medical Association Declaration of Helsinki (adopted by the $18^{\text {th }}$ World Medical Assembly, Helsinki, Finland, June 1964).

The animals were divided into 16 groups $(\mathrm{n}=5)$. In negative control group (NC), the APAP vehicle i.e. $400 \mu \mathrm{l}$ DMSO was only injected. In control group $(C)$, the acetaminophen $(500 \mathrm{mg} / \mathrm{kg}$ b.w) dissolved in $400 \mu \mathrm{l}$ DMSO was i.p injected. In treatment groups, the essential oils prepared from the plants at two different doses i.e. 100 and $200 \mathrm{mg} / \mathrm{kg}$ b.w were diluted in $400 \mu \mathrm{l}$ DMSO and injected i.p immediately after acetaminophen administration. In positive control group, the BHT (10 mg/ $\mathrm{kg}$ b.w) dissolved in $400 \mu \mathrm{l}$ DMSO was injected i.p immediately after acetaminophen administration.

\section{Preparation of tissue homogenate and plasma}

The heparinated blood samples were collected at different time intervals $(2,4,8,16$ and $24 \mathrm{~h}$ after APAP administration) by heart puncture from all the animals and centrifuged at $3000 \times \mathrm{g}$ for $10 \mathrm{~min}$ to obtain plasma. Liver samples were immediately transferred to ice-cold containers and homogenized $(20 \% \mathrm{w} / \mathrm{v})$ in the appropriate buffer using a homogenizer (E.L.M 2500). The homogenate was used to measure biochemical parameters.

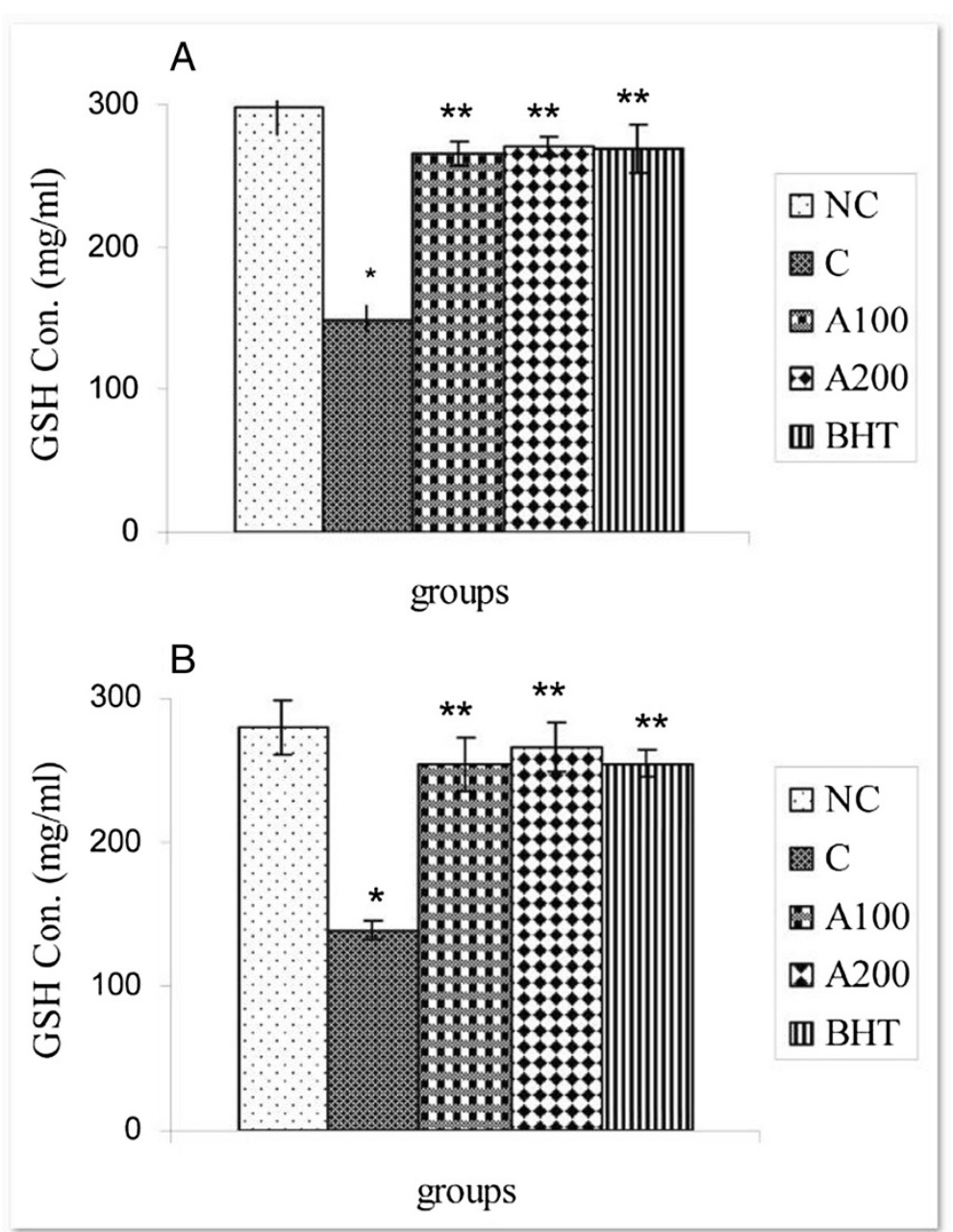

Figure 3 Effect of $\boldsymbol{A}$. wilhelmsii essential oils on GSH levels after APAP administration. (A) $4 \mathrm{~h}$ after APAP administration (B) $8 \mathrm{~h}$ after APAP administration. In negative control group (NC), the APAP vehicle i.e. $400 \mu \mathrm{l}$ DMSO was only injected. In control group (C), the acetaminophen (500 mg/kg bw) dissolved in $400 \mu \mathrm{l}$ DMSO was i.p injected. In treatment groups (A100 and A200), the essential oils prepared from the plants at two different doses i.e. 100 and $200 \mathrm{mg} / \mathrm{kg}$ b.w were diluted in $400 \mu \mathrm{l} \mathrm{DMSO}$ and injected i.p immediately after acetaminophen administration. In positive control group (BHT), the BHT (10 mg/kg b.w) dissolved in $400 \mu \mathrm{l}$ DMSO was injected i.p immediately after acetaminophen administration. Data are mean \pm S.E.M. of five samples obtained from five animals in each group. $\left(^{*}\right)$ denote significantly different from the respective negative control group $(P<0.05)$. $\left.{ }^{* *}\right)$ denote significantly different from the respective control group $(P<0.05)$. 


\section{Biochemical assays GST activity}

Liver cytosolic GST activity were measured spectrophotometrically using CDNB as substrate as described in the instruction of the kit buying from (Biovision, USA).

\section{Cytochrome P450 activity}

CYP activity was performed on liver preparations according to the procedure described in the kit from the (Enzo Life Sciences, Inc., UK).

\section{GSH estimation}

GSH was estimated in liver homogenate based on the protocol of the purchased kit from (BioVision, Inc., USA).

\section{Markers of liver injuries}

To confirm the liver function and injury, serum alanine transaminase (ALT), aspartate transaminase (AST) and alkaline phasphatase (ALP) were determined spectrophotometrically according to the procedure described in the kit purchased from the Pars Azmoon, Co, Iran.

\section{Histophatological studies}

The histological changes were quantitatively analyzed by a veterinary pathologist. All animals were sacrificed $24 \mathrm{~h}$ after acetaminophen administrations. Small portions of liver were excised from the central lobe and were fixed in $10 \%$ buffered formaldehyde solution, embedded in paraffin and sectioned at 6 micrometers. Then, the samples stained with hematoxylin and eosin (H\&E) and studied with light microscope for histological analysis.

\section{Statistical analysis}

Data are presented as means \pm Standard Error of Mean (SEM). The results were subjected to one-way ANOVA followed by Tukey's HSD using SPSS (version 19.0) software. Significant levels were defined as $\mathrm{P}<0.05$.

\section{Results}

Effects of A. wilhelmsii C. Koch essential oils on hepatic GST and CYP450 activities and GSH level in rats treated by APAP

The results in Figure 1A indicated that GST activity was decreased significantly in all time intervals after APAP administration $(\mathrm{P}<0.05)$. Although, the drug administration could significantly affect the GSH level at $4 \& 8 \mathrm{~h}$ after treatment $(\mathrm{P}<0.05)$ (Figure $1 \mathrm{C})$. CYP450 activity was considerably increased at $8 \& 16 \mathrm{~h}$ after APAP administration $(\mathrm{P}<0.05)$ (Figure $1 \mathrm{~B})$. Thus, it is figured out that APAP administration could change the GST activity at 2-24, GSH level at 4 \& 8 h and CYP450 activity at $8 \& 16 \mathrm{~h}$ after treatments. Depending on these changes, these parameters were considered at $4 \& 8 \mathrm{~h}$ after
APAP treatments in experimental rats treated with essential oils.

The data indicated that as reference antioxidant (BHT), the plant essential oils at both doses (100 \& $200 \mathrm{mg} / \mathrm{kg}$ b.w $)$ could modulate the GST and GSH levels at $4 \& 8 \mathrm{~h}$ after APAP administrations as compared to those in control groups. $(\mathrm{P}<0.05)$ (Figures $2 \mathrm{~A}-3 \mathrm{~B})$. Such this result was also seen in CYP450 activity, decreased significantly $8 \mathrm{~h}$ after the essential oils administration at both doses i.e. 100 \& $200 \mathrm{mg} / \mathrm{kg}$ b.w (Figure 4). There is no significant change in CYP450 activities in all groups $4 \mathrm{~h}$ after APAP treatments together with the essential oils (the data not shown).

\section{Effects of A. wilhelmsii C. Koch essential oils on markers of liver injuries in rats treated by APAP}

The ALT activity was significantly increased at $8 \& 16 \mathrm{~h}$ after APAP administration $(\mathrm{P}<0.05)$ (Figure 5A). AST activity was also significantly increased at $8 \mathrm{~h}$ and remained in high level until $24 \mathrm{~h}$ after acetaminophen treatments $(\mathrm{P}<0.05)$ (Figure 5B). As shown in Figure 5C, the ALP activity was not significantly changed in all time intervals as compared to negative control group $(\mathrm{P}>0.05)$. Thus, the ALT and AST activities were examined at $8 \mathrm{~h}$ after APAP treatments in experimental rats treated with plant essential oils. The data indicated that the AST and ALT activities were reduced significantly $8 \mathrm{~h}$ after treatment of rats with the essential oils (200 mg/kg b.w) and BHT as compare to control groups $(\mathrm{P}<0.05)$ (Figure 6A \& B).

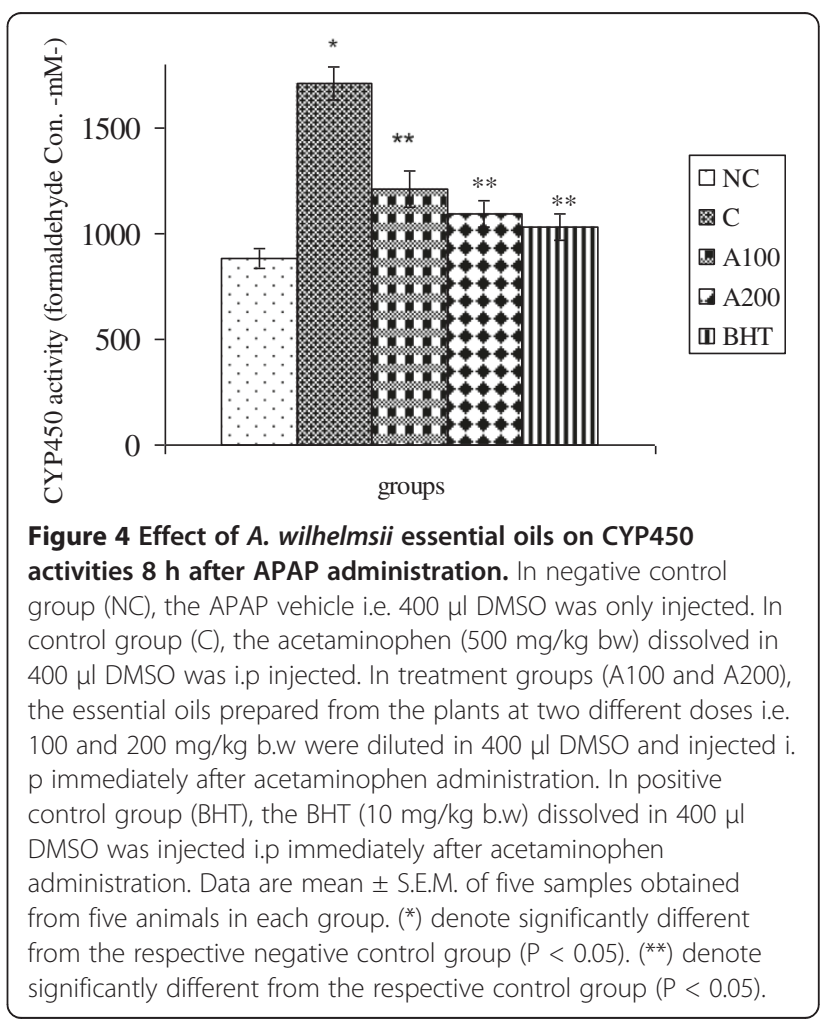




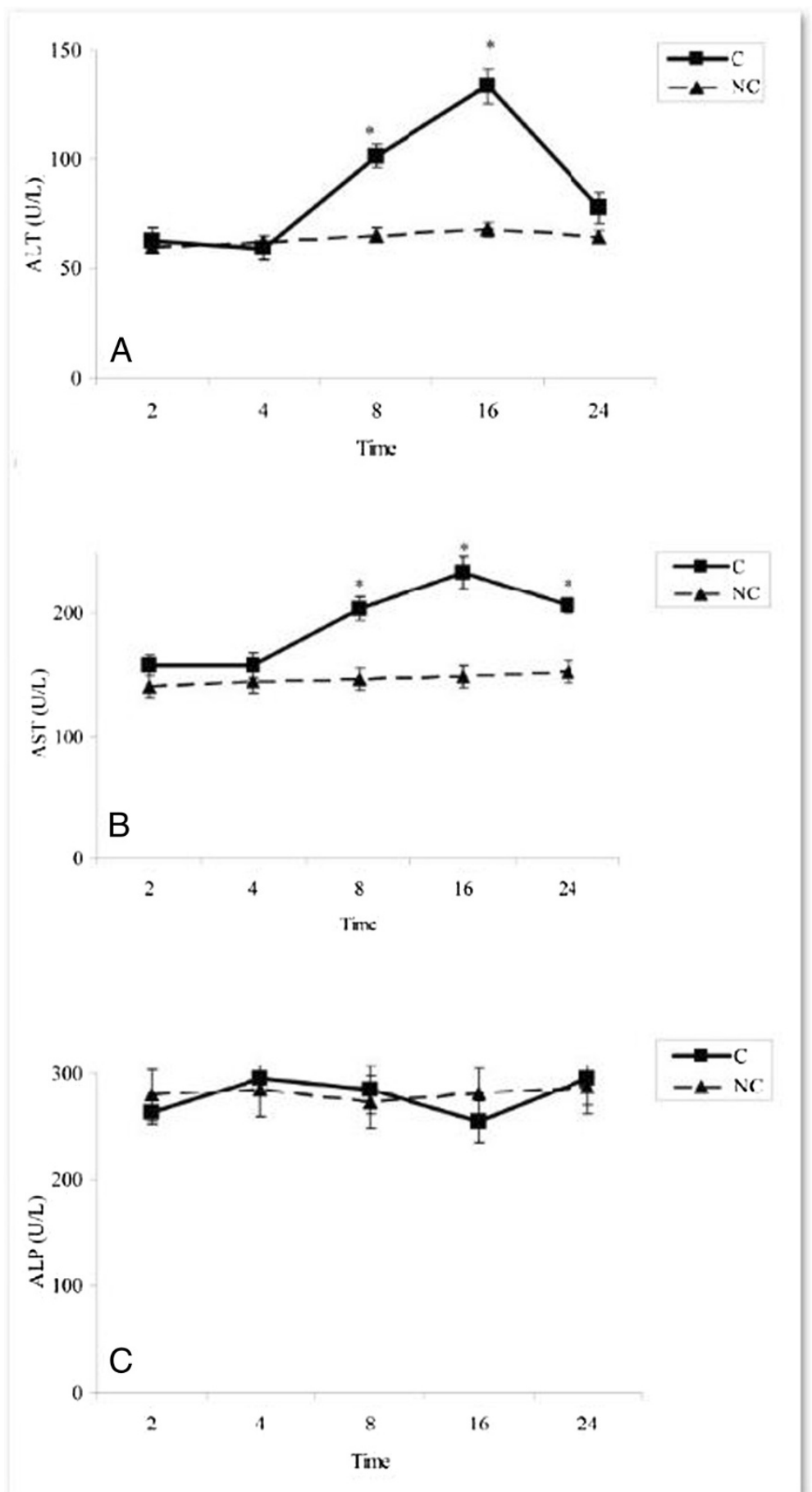

Figure 5 Time-course changes in hepatic function enzyme activities in rats treated with APAP in compare to negative controls. A) ALT activities B) AST activities C) ALP levels. In negative control group (NC), the APAP vehicle i.e. $400 \mu$ l DMSO was only injected. In control group (C), the acetaminophen $(500 \mathrm{mg} / \mathrm{kg}$ bw) dissolved in $400 \mu \mathrm{l}$ DMSO was i.p injected. Data are mean \pm S.E.M. of five samples obtained from five animals in each group. $\left(^{*}\right)$ denote significantly different from the respective negative control group $(P<0.05)$.

Effects of $A$. wilhelmsii C. Koch essential oils on hepatic histophatological changes in rats treated by APAP

Histophatological studies performed on liver biopsies showed normal structure of liver tissue in negative control group (Figure 7A). In liver tissue of rats treated with acetaminophen, minimal 3-8 points of hyalinized cells detected. In some of the cells, wholly white, hyalinized, karyokisis and chromatolysis cytoplasm was also observed. 


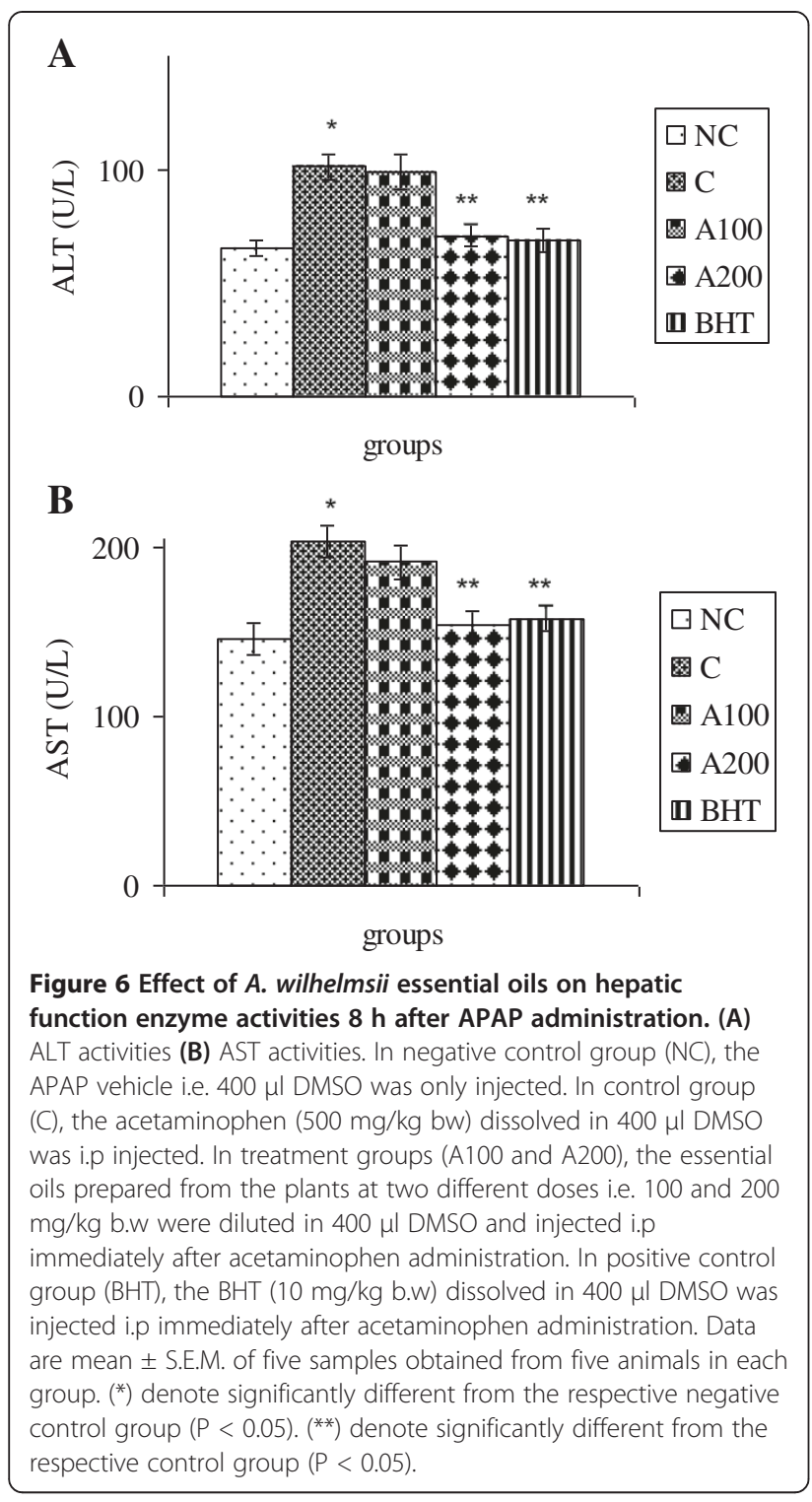

Occasionally, these hyalinized aggregations seems in one parallel row near together affected zonation and distribution of blood in liver (Figure 7B). The necrotic aggregations detected in liver of rats treated with acetaminophen together with $100 \mathrm{mg} / \mathrm{kg}$ b.w of H. Scabrum essential oils were less than those in control group. The histological structures of sinusoids, hepatocytes, veins, arteries and portal spaces were relatively normal (Figure 7C). No necrotic aggregation was observed in rats treated with acetaminophen plus $200 \mathrm{mg} / \mathrm{kg}$ b.w of H. Scabrum essential oils. The sinusoids were some more width and hepatocytes were seemed more basophilic. Some little histological distributions were also observed (Figure 7D). Any effect of necrotic aggregation was not illustrated in rats treated with acetaminophen plus BHT. The histological structures of sinusoids, hepatocytes, veins, arteries and portal spaces were perfectly normal (Figure 7E).

\section{Discussion}

The present study indicated that i.p administration of Achillea wilhelmsii crude extract oil to APAP-treated rats significantly inhibited hepatic injuries induced by acetaminophen. Our biochemical data indicated that the mechanism by which Achillea wilhelmsii essential oils inhibited hepatic toxicity is by modulating the APAP detoxification pathways in the liver which mediate detoxification and metabolic disposal of the intermediate reactive product (NAPQI) leading to inhibition of toxicity process. In this connection, the essential oils $(100 \& 200 \mathrm{mg} / \mathrm{kg}$ b.w) decrease the activities of CYP450 and serum transaminases (ALT and AST) elevated in the liver of APAP treated rats (Figures $4 \&$ \&). Likewise, the decreased hepatic GSH and GST activity in APAP treated rats is compensated by both doses of the essential oils (Figures 2A-3B).

The current findings relating to the effects of Achillea wilhelmsii essential oils on APAP-induced hepatic detoxification enzymes are consistent with those of several previous reports that medicinal plants exert their protective effects by modulating the reactive metabolite in the liver (Liu et al. 1995; Kim et al. 2004; Oliveira et al. 2005). Suppression of CYP450 by the essential oils (Figure 4) diminished the formation of APAP reactive metabolite which is leaded to its lower toxic effects (Dong et al. 2000; Hendrickson and Kenneth 2006; Borne 1995).

On the other hand, many studies have indicated that decreased toxicity can be achieved through the modulation of the GST activity (Henderson et al. 2000). GST is a biotransformation enzyme in phase II involved in the detoxification of xenobiotics by conjugating these toxic substances with GSH, ultimately protecting cells and organs against drug-induced toxicity. Reduction of GST activity together with GSH depletion (Figure 1A \& C) in liver of APAP-treated rats may be due to its effective role in detoxification of reactive metabolite of APAP (Henderson et al. 2000). Increasing of GST in liver by Achillea wilhelmsii essential oils which use GSH as substrate (Figures 2A-3B) might advice to more metabolic disposal of APAP metabolites, resulting in the protection of hepatocytes and simultaneous inhibition of toxicity. On the other hand, it was found that GST and GSH is induced upon oxidative stress (Moghadasian et al. 1996; Toyokuni et al. 1995). In addition, GST, a secondary antioxidant enzyme used in drug detoxification, helps in the radical-scavenging activity of GSH (Kumari and Kakkar 2012). Therefore, the GST induction following essential oil treatments may reflect a decreased oxidative stress arising from the oxygen radical scavenging activity of Achillea wilhelmsii essential oils. 

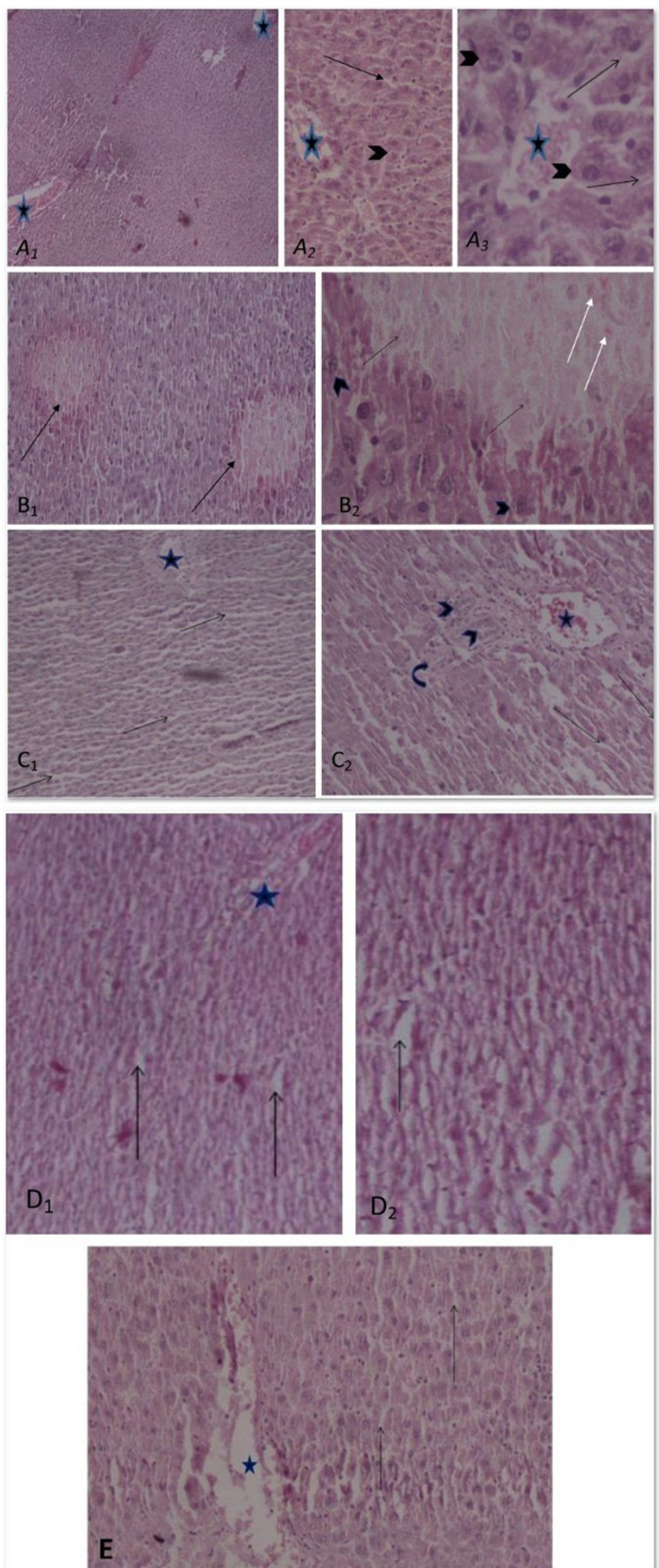

Figure 7 (See legend on next page.) 
(See figure on previous page.)

Figure 7 Effect of $A$. wilhelmsii essential oils on histopathological changes $\mathbf{2 4} \mathrm{h}$ after APAP administration. Light microscopy showed histologic sections of liver of rats from different groups of animals. A: Section of liver from negative control group (NC). Normal structure of liver tissue with normal central vein (stars) is detected. Normal sinusoid (arrow) between hepatocyts (arrow head) which form hepatic cords $\left(\mathbf{A}_{\mathbf{1}}\right.$ : original magnification $\times 40, \mathbf{A}_{\mathbf{2}}: \times 100$ and $\mathbf{A}_{\mathbf{3}}: \times 400$ ). B: Section of liver from control group (C) (acetaminophen (500 mg/kg bw)). B1: Liver section with necrotic hyalinized aggregation in perilobular zone (arrow) and disarray of hepatic lobule and hepatic cords ( $\mathbf{B}_{\mathbf{1}}$ : original magnification $\left.\times 100\right)$. $\mathbf{B}_{\mathbf{2}}$ : This section shows hepatocytes necrosis with acidophil bodies (white arrow) and kariolysis (black arrow) in necrosis area. Their nucleuses are comparative with around normal hepatocyte nucleus. The hepatocyte cytoplasm, hepatic sinusoid and hepatic cord are disarray $\left(\mathbf{B}_{2}\right.$ : original magnification $\times 400$ ). C: Section of livers from treatment group (APAP+ $100 \mathrm{mg} / \mathrm{kg}$ b.w essential oils) $\mathbf{C}_{\mathbf{1}}$ : The necrotic regions were not observed and sinusoids (arrows), hepoatocytes and veins (star) are relatively normal (original magnification $\times 40$ ). $\mathbf{C}_{\mathbf{2}}$ : Section from preportal and portal space which triad [arteries (bend arrow), bile ducts(arrow head) and portal vein] are normal (original magnification $\times 100$ ). D: Section of livers from treatment group (APAP+ $200 \mathrm{mg} / \mathrm{kg}$ b.w essential oil) without of any necrotic zone. Bigger sinusoids (arrow), smaller and more basophilic hepatocytes were observed. The histological structures are relatively disarray $\left(\mathbf{D}_{1}\right.$ : original magnification $\left.\times 40, \mathbf{D}_{2}: \times 100\right)$. $\mathbf{E}$ : Section of liver from positive control group (BHT (10 mg/ kg b.w)) without any necrotic zone, sinusoids (arrows) and hepatocytes around of central vein are normal (star) (original magnification $\times 100$ ).

According to the decline in hepatic GSH content (Figure 1C), it was evident that paracetamol-induced toxicity involved a change in cellular redox status toward a state of oxidative stress. A wide variety of oxidizing molecules such as ROS and/or depleting agents can alter glutathione redox state, which is normally maintained by the activity of GSH-depleting (GPx, GST) and GSHreplenishing (GR) enzymes (Halliwell 1996). Therefore, it can be assumed that decreasing in the GSH concentration might cause the effectiveness of GST and GPx activity to be restricted, as evident by the intensification of lipid peroxidation (Czeczot et al. 2006). The APAP induced depletion of GSH was restored by essential oil treatment (Figure 3A \& B), which supported the involvement of exogenous administration of antioxidants in modulation of GSH metabolism. Thus, Achillea wilhelmsii essential oils may play a key role against APAP intoxication by influencing the cellular GSH pool.

In the present work, the Achillea wilhelmsii essential oil also inhibits APAP induced liver damages as demonstrated by the decreasing in plasma transaminases activities (Figure 6A \& B). The extent of hepatic damage is assessed by the level of released cytoplasmic transaminases (ALT and AST) in circulation (Chenoweth and Hake 1962; Sallie et al. 1991). ALP is a transmembrain protein in bile canalicules and releases in blood circulation when the canalicules blocked or disturbed. The maintenance of plasma ALP level in all groups indicates that hepatic damages don't affect the bile canalicules. The binding of NAPQI with cellular proteins leads to necrosis in liver (Dahlin et al. 1984), which subsequently alters the liver function tests. The observed hepatoprotective effect might be a consequence of the stabilization in the redox state and maintenance of the antioxidant capacity offered by Achillea wilhelmsii essential oils. Other studies also confirming these results indicating the protective effect of Cyperus Scariosus and Artemisia absinthium extract on acetaminophen induced hepatotoxicity have been shown via lowering the respective serum AST and ALT (Gilani and Janbaz 1995a, b). Protective effect of $\alpha$ - and $\beta$-amyrin, a triterpene mixture from Protium heptaphyllum (Aubl.) March. trunk wood resin, against acetaminophen-induced liver injuries in mice through diminution in oxidative stress and toxic metabolite formation was also reported (Oliveira et al. 2005). One study showed the protective effects of quercetin and curcumin on paracetamol-induced liver injury in rat through mitigation the rise in markers of liver injuries such as AST and ALT (Yousef et al. 2010). In addition, Propolis extract exhibited curative effects by reversing APAP induced alterations in blood biochemical variables, CYP enzymes and markers of oxidative stress (Bhadauria and Nirala 2009). Lupeol when co-administered with APAP effectively reduces oxidative stress and prevents APAP-induced hepatotoxicity by increasing the intracellular defense mechanism consisting of various antioxidant enzymes (SOD, CAT, GST, GR and GPx) (Kumari and Kakkar 2012). These data were confirmed by histophatological examinations (Figure 7) indicating administration of essential oils decreases the oxidative hepatic injuries such as necrotic aggregations in acetaminophen treated rats.

\section{Conclusion}

Our results indicated that Achillea wilhelmsii essential oils may have protective role against APAP induced hepatic damages by reducing the formation of the active intermediate APAP metabolite through modulating of acetaminophen-metabolizing enzyme activities, such as GST and CYP450. These data validates the traditional use of plant in hepatic damages.

\section{Endnote \\ aacetyl-para-aminophenol.}

\section{Competing interest}

The authors declare that they have no competing interest.

Authors' contribution

All authors read and approved the final manuscript. 


\section{Author details}

${ }^{1}$ Department of Medicine, Faculty of Medicine, Qom Branch, Islamic Azad University, Qom, Iran. ${ }^{2}$ Nuclear Fuel Cycle Research School, Nuclear Science and Technology Research Institute, Tehran, IR, Iran. ${ }^{3}$ Department of Anatomy, Faculty of Medicine, IUMS, Tehran, Iran. ${ }^{4}$ Department of Physiology, Faculty of Science, Qom Branch, Islamic Azad University, Qom, Iran. ${ }^{5}$ Department of Biochemistry, Faculty of Sciences, Payame-e-Noor University, Tehran, Iran.

Received: 7 September 2012 Accepted: 6 December 2013

Published: 24 March 2014

\section{References}

Asgary S, Naderi GH, Sarrafzadegan N, Mohammadifard N, Mostafavi S, Vakili R (2000) Antihypertensive and antihyperlipidemic effects of Achillea wilhelmsii. Drugs Exp Clin Res 26(3):89-93

Benedek B, Geisz N, Jager W, Thalhammer T, Kopp B (2006) Choleretic effects of yarrow (Achillea millefolium s.l.) in the isolated perfused rat liver. Phytomedicine 13:702-706

Bhadauria M, Nirala SK (2009) Reversal of acetaminophen induced subchronic hepatorenal injury by propolis extract in rats. Environ Toxicol Pharmacol 27:17-25

Bond GR, Wiegand CB, Hite LK (2003) The difficulty of risk assessment for hepatic injury associated with supra-therapeutic acetaminophen use. Vet Hum Toxicol 45:150-153

Borne RF (1995) Nonsteroidal anti-inflammatory drugs. In: Foye WO, Lemke TL, Williams DA (eds) Principles of medicinal chemistry, 4th edn. Williams \& Wilkins, pp 544-545

Boyer TD, Rouff $L$ (1971) Acetaminophen-induced hepatic necrosis and renal failure. J Am Med Assoc 218:440-441

Candan F, Unlu M, Tepe B, Daferera D, Polissiou M, Sokmen A, Akpulat HA (2003) Antioxidant and antimicrobial activity of the essential oil and methanol extracts of Achillea millefolium subsp. millefolium Afan. (Asteraceae). J Ethnopharmacol 87:215-220

Cavalcanti AM, Baggio CH, Freitas CS, Rieck L, de Sousa RS, Da Silva-Santos JE, Mesia-Vela S, Marques MC (2006) Safety and antiulcer efficacy studies of Achillea millefolium L. after chronic treatment in Wistar rats. J Ethnopharmacol 107:277-2784

Chenoweth MB, Hake CL (1962) The smaller halogenated aliphatic hydrocarbons. Ann Rev Pharmac 2:363-398

Czeczot H, Scibior D, Skrzycki M, Podsiad M (2006) Glutathione and GSHdependent enzymes in patients with liver cirrhosis and hepatocellular carcinoma. Acta Biochim Pol 53:237-242

Dadkhah A, Fatemi F, Kazemnejad S, Rasmi Y, Ashrafi-Helan J, Allameh A (2006) Differential effects of acetaminophen on enzymatic and non-enzymatic antioxidant factors and plasma total antioxidant capacity in developing and adult rats. Mol Cell Biochem 281:145-152

Dadkhah A, Allameh AA, Fatemi F, Rasmi Y, Ashrafihelan J (2007) Considering the pathologic lesions of liver and changes of plasma alanine transaminase and aspartate transaminase in acetaminophen-induced toxicity in rat. Pharm Sci 2:47-54

Dahlin DC, Miwa GT, Lu AY, Nelson SD (1984) N-Acetyl-p-benzoquinoneimine: a cytochrome P-450-mediated oxidation product of acetaminophen. Proc Natl Acad Sci U S A 81:1327

Dong H, Haining RL, Thummel KE, Rettie AE, Nelson SD (2000) Involvement of human cytochrome P450 2D6 in the bioactivation of acetaminophen. Drug Metab Dispos 28:1397-1400

Fathi H, Lashtoo Aghaee B, Ebrahimzadeh MA (2011) Antioxidant activity and phenolic contents of Achillea wilhemsii. Pharmacologyonline 2:942-949

Gilani AUH, Janbaz KH (1995a) Studies on protective effect of Cyperus Scariosus extract on acetaminophen and CCl4-induced hepatotoxicity. Gen Pharmacol Vasc Syst 26:627-631

Gilani AUH, Janbaz KH (1995b) Preventive and curative effects of Artemisia absinthium on acetaminophen and CCl4-induced hepatotoxicity. Gen Pharmacol Vasc Syst 26:309-315

Goldberg AS, Mueller EC, Eigen E, Desalva SJ (1969) Isolation of the anti inflammatory principles from Achillea millefolium (Compositae). J Pharm Sci 58:938-941

Halliwell B (1996) Antioxidants in human health and disease. Ann Rev Nutr $16: 33-50$
Hawkins LC, Edwards JN, Dargan PI (2007) Impact of restricting paracetamol pack sizes on paracetamol poisoning in the United Kingdom: a review of the literature. Drug Saf 30:465-479

Henderson CJ, Wolf CR, Kitteringham N, Powell H, Otto D, Park BK (2000) Increased resistance to acetaminophen hepatotoxicity in mice lacking glutathione S-transferase Pi. Proc Natl Acad Sci U S A 97:12741-12745

Hendrickson RG, Kenneth EB (2006) Acetaminophen. In: Nelson LH, Flomenbaum N, Goldfrank LR et al (eds) Goldfrank's toxicologic emergencies. McGraw-Hill, New York, p 525

Khashab M, Tector AJ, Kwo PY (2007) Epidemiology of acute liver failure. Curr Gastroenterol Rep 9:66-73

Kim KA, Lee JS, Park HJ, Kim JW, Kim CJ, Shim IS, Kim NJ, Ham SM, Lim S (2004) Inhibition of cytochrome P450 activities by oleanolic acid and ursolic acid in human liver microsomes. Life Sci 74:2769-2779

Kumari A, Kakkar P (2012) Lupeol prevents acetaminophen-induced in vivo hepatotoxicity by altering the $\mathrm{Bax} / \mathrm{BCl}-2$ and oxidative stress-mediated mitochondrial signaling cascade. Life Sci 90:561-570

Larson AM, Polson J, Fontana RJ, Davern TJ, Lalani E, Hynan LS, Reisch JS, Schiødt FV, Ostapowicz G, Shakil AO, Lee WM (2005) Acute Liver Failure Study Group. Acetaminophen-induced acute liver failure: results of a United States multicenter, prospective study. Hepatology 42:1364-1372

Laskin DL, Gardner CR, Price VF, Jollow DJ (1995) Modulation of macrophage functioning abrogates the acute hepatotoxicity of acetaminophen. Hepatology 21:1045-1050

Liu J, Liu Y, Parkinson A, Klaassen CD (1995) Effect of oleanolic acid on hepatic toxicant-activating and detoxifying systems in mice. J Pharmacol Exp Ther 275:768-774

Michael SL, Pumfod NR, Mayeux PR, Niesman MR, Hinson JA (1999) Pretreatment of mice with macrophage inactivators decreases acetaminophen hepatotoxicity and the formation of reactive oxygen and nitrogen species. Hepatology 30:186-195

Moghadasian MH, Freeman HJ, Godin DV (1996) Endogenous antioxidant status in neoplastic and adjacent tissues in 1,2-dimethylhydrazine-induced colon cancer in rats: effects of olsalazine. Carcinogenesis 17:983-987

Nemeth E, Bernath J (2008) Biological activities of yarrow species (Achillea spp.). Curr Pharm Des 14:3151-3167

Oliveira FA, Chaves MH, Almeida FRC, Lima RCP Jr, Silva RM, Maia JL, Brito GAAC, Santos FA, Rao VS (2005) Protective effect of $\alpha$ - and $\beta$-amyrin, a triterpene mixture from Protium heptaphyllum (Aubl.) March. trunk wood resin, against acetaminophen-induced liver injury in mice. J Ethnopharmacol 98:103-108

Roshanaei K, Dadkhah A, Fatemi F, Kazemi M, Rezaei MB, Alipour M (2012) Study of the chemical composition and antioxidant properties of Iranian Achillea wilhelmsii C. Koch essential oils and hydroalcoholic extracts from Qazvin area. App Biol 1:73-82

Sallie R, Tredger JM, William R (1991) Drugs and the liver. Biopharmaceut Drug Dispos 12:251-259

Sener G, Sehirli AO, Ayanoğlu-Dülger G (2003) Protective effects of melatonin, vitamin $\mathrm{E}$ and $\mathrm{N}$-acetylcysteine against acetaminophen toxicity in mice: a comparative study. J Pineal Res 35:61-68

Toyokuni S, Okamoto K, Yodoi J, Hiai H (1995) Persistant oxidative stress in cancer. FEBS Lett 358:1-3

Vermeulen NPE, Bessems JGM, De Straat V (1992) Molecular aspect of paracetamol - induced hepatotoxicity and its mechanism based prevention. Drug Metabol Rev 24:367-407

Yaeesh S, Jamal Q, Khan AU, Gilani AH (2006) Studies on hepatoprotective, antispasmodic and calcium antagonist activities of the aqueous-methanol extract of Achillea millefolium. Phytother Res 20:546-551

Yousef MI, Omar SAM, El-Guendi MI (2010) Potential protective effects of quercetin and curcumin on paracetamol-induced histological changes, oxidative stress, impaired liver and kidney functions and haematotoxicity in rat. Food Chem Toxicol 48:3246-3261

doi:10.1186/1999-3110-55-37

Cite this article as: Dadkhah et al:: Potential preventive role of Iranian Achillea wilhelmsii C. Koch essential oils in acetaminophen-induced hepatotoxicity. Botanical Studies 2014 55:37. 